\section{THE PLACE OF SCIENCE IN INDUSTRY}

$\mathrm{A}^{\mathrm{s}}$ S was stressed by Sir Richard Gregory in his introductory address, and again by Sir Harold Hartley in summing up at the final session, the twoday conference on "The Place of Science in Industry", arranged by the Division for the Social and International Relations of Science of the British Association on January 12 and 13, and held at the Royal Institution, was no mere repetition of discussions on scientific and industrial research, or the relations of science and industry to be found in numerous recent reports. It could not be claimed that fresh ideas in regard to the strategy and tactics of research or its organization were ventilated at the Conference, though some of the war-time achievements of science were disclosed for the first time to a wider circle. The subject was viewed essentially in its social setting, and the Conference was a definite attempt to further that task of public education upon which the adequate support of research depends. Unless there is general understanding of the achievements and the possibilities of scientific research, we cannot expect that there will be forthcoming the public support, either of finance or of men, on which the expansion of our scientific effort to meet the post-war demands and opportunities ultimately depends.

As Sir Harold Hartley pointed out, the Conference had two main objects : to give the public a detailed idea of the contributions of science in industry, and to give a clearer view of what should be our strategy and tactics in this field. Its organization was thus in harmony with the educational work of the British Association in the field of nutrition to which, at the final session, Lord Woolton paid such a generous and emphatic tribute. If a tribute no less emphatic and generous should be paid to the Association by some future Minister of Production for its work in this field in promoting general interest and understanding of the place and application of science in industry, it may well be for the balanced and lucid presentation of the subject which characterized the recent Conference. * Sir Richard Gregory dealt with some of the popular misconceptions of the past and referred to the impossibility of a sharp separation between research workers in pure and in applied science, or again of separating scientific workers from other citizens in their social duties and responsibilities. He urged that there must be a two-way traffic between science and industry if we are to be in the van of progressive life and service. Advances on this united front would raise standards of living and strengthen the social structure if they are correlated with humanistic national policy. Public opinion would not now tolerate the deplorable social effects of the introduction of new powers and processes of a century or more ago.

Referring even more emphatically than Sir Richard Gregory to the lag between scientific knowledge and social wisdom, Mr. Ernest Bevin, who presided over the first session, on "What Industry Owes to Science", commented on the greater receptivity of industry to scientific ideas in war-time than in time of peace. The time lag, he believes, is due partly to faults in the management or directorate in industry, and partly to traditions of the past. $\mathrm{He}$ urged closer study of the problem of how best to bring the benefits of scientific discovery into the lives of the people so that they can be enjoyed by the masses as quickly as possible and at a price within their reach. The people should, as it were, have a vested interest in a scientific discovery.

Following on Mr. Bevin's plea for social and economic research-and it was notable that the Conference was never allowed to forget such aspectsthe session considered some of the industrial achievements of science in a way which should win the support of any trade unionists who tend to look askance at science. Lord Brabazon's dry humour played delicately over the achievements of aviation, emphasizing the immense potentialities opened up by jet propulsion with its gas engine, revolutionizing aeroplane design and speed, with possibilities as power units in other fields. He referred to the important part which the universities must take in such fields, the necessity of full freedom for the fundamental research worker, with no dictation as to the detailed direction of his work. Sir Robert Watson-Watt followed with a paper on telecommunications, in which once again the repercussion on, and stimulation of, other industries by research in a particular industry was stressed. Distinguishing between the internal science and external science with reference to an industry, the former being scientific effort oriented towards the direct solution within the parent technique of the industry of problems peculiar to the industry, Sir Robert said that the telecommunications industry has been exceptional, and exceptionally fortunate, in its utiliza. tion of external science. He instanced the demands it has made on the metallurgist for metals, on the inorganic chemist for dielectrics, basic materials and coatings, and glasses which 'wet' the metals used in the vacuum tubes, on the organic chemist for dielectrics for cables, on the crystallographer, the electron phy icists, on those expert in classical optics, acous tics, geophysics and solar physics.

Much the same, if less extensive, stimulating interplay between industry and the sciences and between industries was revealed in Dr. W. T. Astbury's paper on synthetic fibres. Dr. Astbury pointed first to the close relations between textiles and biology, and then to their relations with the plastics industry, and to the part played in recent developments by such a tool as X-rays. The reasoned, scientific development of regenerated protein fibres is a direct consequence of $\mathrm{X}$-ray studies carried out in a university. Again, such synthetic fibres are really supplementary to natural fibres and not just substitutes; they increase textile potentialities, and at the present rate of progress and in a sane economic world there is no knowing to what heights science may lead the textile industries. Dr. Astbury strikingly emphasized the indivisibility of science, pointing out that the study of wool and the study of muscle are not easily separated, and Prof. J. D. Bernal, in summing up, said that science and industry are two aspects of one principle: we must find the proper relation between the organization of science and industry, always remembering that it should be a two-way traffic. Whereas in the older industries the process may be mainly one of infiltration of science, in the newer industries the discussions indicated that the most conspicuous feature might be the stimulation of science by industry.

Opening the afternoon session on "Fundamental Research in Relation to Industry", Lord McGowan, who presided, suggested that we should consider as fundamental any research which is primarily directed to increasing our understanding of the causes of phenomena and of the principles and generalizations which make up the so-called 'laws' of Nature. Com- 
menting on the development of our knowledge of plant design, he suggested that what is commonly termed the 'safety factor' to allow a sufficient margin of size would be more aptly described as the 'ignorance factor'. Research in the chemical industry can be described as of four types: that directed to maintain and improve the quality of products and economical working; chemical engineering research; that into problems of industries served by chemical industry, such as agriculture; and speculative research, such as that in the high-pressure field, of which polythene has been the outcome. On this Lord McGowan commented that it is difficult to ensure the continuous prosecution of fundamental research in a laboratory where interesting and exciting industrial developments are taking place. The bulk of the fundamental research should be carried on in university laboratories, though some would be carried out in Government laboratories, and Lord McGowan said that Imperial Chemical Industries Ltd. has decided to establish a special laboratory for fundamental research, administratively and geographically separated from works laboratories.

Lord McGowan was followed by a trio of brilliant papers which should effectively dispose of the view once entertained at British Association meetings that engineers have the monopoly of lucid exposition and clear delivery. Prof. P. M. S. Blackett, dealing with physics, urged that research should be directed to cheapening the production of good articles and not simply towards increasing the number of faney articles, and referred to unfavourable factors in our economic system which require attention. He urged that close relation between pure and applied research is essential and condemned the snobbery which sometimes hinders such contacts. More genenous support for fundamental research is required, and he pleaded for more corporate action by scientific bodies such as the Royal Society and professional bodies in reviewing the country's scientific resources, their disposition, and the planning of policy. To do this, staff will be essential and a watch should be kept over the effect of chance discoveries. Our main task is to ensure, first, the application of science in raising the standard of living; the prosecution of science as a cultural or intellectual interest will follow. If Prof. Blackett's observations were general, Prof. E. C. Dodds kept strictly within the field of biochemistry, using the discoveries of penicillin, of insulin and of the synthetic estrogens to illustrate the immense potentialities of biochemistry for human life, especially in the Middle and Far East, where the repercussions on population problems may be profound. All these discoveries arose in academic laboratories, and the first need is to encourage fundamental research and provide the investigator with every facility to experiment merely for the sake of experimenting.

Dr. C. D. Darlington, in discussing the unity and power of biology, gave a no less fascinating picture of the implications of biology in the field of plant and animal breeding, of the control of diseases of crops, and of such human scourges as cancer. The teaching of biology, he urged, is thirty years out of date, and that will delay the fruition of the unity and power which he described. From what we know of different modes of activity of proteins, common fundamental principles are emerging, which will provide an intellectual and a material power which will make life very different for us all. Dr. D. P. Riley, who followed, in spite of the fact, which he duly noted, that the speakers at the Conference included five eminent in X-ray work, made the mistake of attempting to cover too wide a field in the time, and his enumeration of the many fields of application of X-rays in science and industry was too ill prepared to leave him the opportunity to develop adequately his remarks about the training courses in X-ray work at Cambridge to ameliorate the shortage of X-ray workers, or on the importance of freedom of publication of scientific research both as a stimulus to research and an incentive to the investigator.

The session on the morning of January 13, over which Sir John Greenly presided, was devoted to industrial research and development, and brought some more impressive evidence of British technical achievements and the impact not only of science on industry, but also of one industry on another. Sir John Greenly, confining himself to general observations, reaffirmed his own conviction that science has contributed and will continue to contribute immeasurably to sucoessful industrial enterprise. Quoting from Marcus Aurelius, he urged that to investigate systematically and truly all that came under our observation is exactly what we expect of science in its application to industry. Besides the contribution of new ideas and prospects from fundamental research leading to new inventions, there is, scarcely less important, the continuous help given to the normal conduct of a business by indicating improved methods of production and suggesting the use of new materials. $\mathrm{He}$ cited welding as a particularly good illustration of the way in which science has helped to make an industry more efficient and, by providing a new and better technique, assisted in solving the problems of export and full employment. Finally, he stressed the importance of full co-operation and team-work on the part of all concerned, and above all of giving the scientific worker the fullest opportunities in order to enable him to continue to be the pathfinder of industry.

Dr. C. Sykes followed with a review of the general field of metallurgy, in which he pointed out that there is no hard and fast line between research and development. Dr. Sykes emphasized the cost of development work and the dependence of the rate of development on the degree of confidence it establishes between suppliers and users. With regard to post-war development, he foresees four types of problems and needs : the proper allocation of the available technical personnel; the adequate development of schools for research at the universities; the encouragement of enterprise, in which connexion he welcomed the Chancellor of the Exchequer's recent concessions with regard to obsolescence ; and the furthering of collaboration between industries. It was natural enough that Dr. S. G. Hooker's account of the development of the Merlin engine and of what those developments have meant in extending the carrying power, climbing power, speed and general performance of aircraft in service with the Royal Air Force should have attracted most attention at this session of the Conference. His paper provided a striking illustration of technical and scientific development stimulated by the War; but Mr. W. C. Devereux's paper on research and development applied to light alloys was more instructive with regard to the main purpose of the session. Mr. Devereux gave a most striking picture of the way in which scientific advances, such as Dr. W. HumeRothery's brilliant work in metallurgical physics at Oxford, and new techniques such as X-ray diffraction, are opening up new possibilities in this field. Like Lord McGowan, he referred to the twin function of 
the universities in advancing knowledge of science and in providing industry with men qualified to interpret this new knowledge. Industry also must play its part by making scientific posts sufficiently attractive to ensure a steady stream of the right type of men through the universities. He also suggested that the universities might take stock of the position arising out of the demand for scientific men fully qualified for the higher posts in research management and administration, for which there is at present an undoubted lack of suitable men. Mr. Devereux commented on the way in which the volume of routine testing is increased by lack of fundamental knowledge of the properties of materials; and describing the aevelopment work at Light Alloys Ltd., said that in addition to a Process Development Department dealing with the development of new processes and improvement of old processes within the scope of their normal activities, there is an Engineering Development Department concerned with the development of new ideas and the engineering uses of the products manufactured. Dr. J. C. Swallow, in the course of a brilliant short paper on plastics, contrived to give not only a lucid exposition of the structural relations of the synthetic organic thermoplasties, such as polymethyl methacrylate, polyvinyl chloride, nylon, polythene, polyisobutylene, but also to demonstrate the variations in their properties, with a deftness and nonchalance that a conjurer might have envied. This he followed up by indicating clearly and concisely what is involved in the industrial development of such products: the close cooperation of the organic and the physical chemist, the physicist, the chemical engineer and the engineer, and the importance of the development of knowledge of the fundamental principles of plastic flow, and the perfection of methods of measurement both in regard to the application and the manufacture of plastics, though Dr. Swallow observed that in such industrial developments there is art as well as science. Above all, it is important to have available as many clarifying principles as science can provide, relating properties to structure, in order to be able to select and concentrate on the development of those plastics likely to be the most useful and to prevent dissipation of research effort.

The story which Mr. A. L. Bacharach had to tell of the synthetic vitamin industry was no less fascinating; and if the session seemed to come to a lame conclusion and the red lights came on insistently for the first time, it was rather because of Mr. Bacharach's failure to prepare his material adequately with reference to the time factor, so that discussion of the questions to which his account of the development and possibilities of this new industry, not merely for therapeutics, but also in nutrition and the food industries generally, naturally led, was prematurely terminated. Mr. Bacharach pointed out that this new branch of chemical industry is less than twenty years old, and that not all the products are in the strict sense synthetic; they may be extracted from natural sources or degraded from natural compounds. All the important discoveries on which the industry is based were made in university or institutional laboratories, and even the isolation, purification or determination of constitution was effected in such laboratories and not in industrial laboratories. The type of problem is one calling almost solely for the co-operation of the organic chemist and the chemical engineer. Finally, Mr. Bacharach emphasized the identity of the natural and synthetic vitamins, and the widely varying scale on which the various processes of manufacture are carried on.

The final session of the Conference was devoted to "The Future: What Science might Accomplish", and in presiding over this session, Lord Woolton spoke of the lessons for peace of war-time triumphs. Rejecting alike the totalitarian approach with its abandonment of freedom and the laissez-faire doctrine of trusting to chance, Lord Woolton believes that public opinion will demand that in certain spheres the Government should exercise a greater influence than it did before the War, and that if we use the knowledge we have gained of necessity in war, we have much material on which to reconstruct a healthier and happier society in the future. Within a few weeks of his taking office as Minister of Food in April 1940, we were faced with a 50 per cent drop in our food imports, and were saved from starvation by the application of scientific knowledge to the problem of securing the right foods, not to satisfy our appetites, but to meet nutritional needs. Advances which scientific research has made in handling food, such as dehydration, both saved shipping space and preserved food, while in agriculture scientific research has made it possible to increase yields beyond all expectation. Steps taken to increase the consumption of milk, to encourage the eating of selected vegetables, to provide certain classes with orange juice, cod-liver oil, vitamins and calcium tablets, to develop communal feeding and meals in factories, and to expand the scheme for meals in schools, should form a permanent part of our health programme. Lord Woolton urged the British Association to continue its educational work in the field of nutrition, and said that in the fields of housing, in trade and industry, and the effective use of manpower, we should also seek to turn to account the lessons and experience of the War. He fully agrees that post-war reconstruction should begin with housing : that involves determining the standard of housing that will enable people to live healthy lives, and then the application of scientific knowledge to the design and construction of houses.

For the best uses to be made of our scientific resources, there must be closer contact between scientific workers in industry and those in the universities, more integration between research and development, and more pooling of information about new developments. The State and industry must see that scientific research, whether medical, agricultural, industrial or fundamental, is adequately endowed.

Mr. E. Carter followed with a paper on science and housing, in which he pointed out that the comparatively few advanced modern houses built between the Wars must be regarded as laboratory models rather than parts of a housing achievement. He urged that housing should be considered as primarily a social problem, taking account of potentialities rather than actualities. The contribution of science, he suggested, has three aspects : definition of the problem, which involves a large extension of a scientific survey of the attitudes of people to their domestic life and equipment, of the dynamies of family living, and of the physical factors that govern house plan and equipment, sizes and shapes. Secondly, we have to provide solutions, bring all our techniques, material and equipment to a high pitch of efficiency and to coordinate them into integrated designs for dwellings and communities. Finally, there is the operations stage--the business of economics, scientific manage- 
ment, production and job supervision. Scientific workers, said Mr. Carter, are not happy working to make low standards tolerable, nor will they for long be content to design high standards which cannot be translated into the real life of the mass of the people.

No brief summary could do justice to this highly suggestive paper or to those which followed from Sir Joseph Barcroft on food and from Prof. J. M. Mackintosh on health. Sir Joseph Barcroft, pointing out how little we know of nutrition in regard to the brain, gave a glimpse of the possibilities if the nourishment of our central nervous system could be placed on an ascertained basis. Predicting a great change within ten years with regard to the certainty of our knowledge of the relation of food to man, Sir Joseph indicated some of the problems, such as those of flavour, requiring investigation, and the decisions which will have to be taken in regard to milk policy, meat policy and the like. He also referred to the shortage of research workers; many more will be required to prosecute on any adequate scale the investigations on the nutritional demands of muscular exercise, mental work and maternal potentiality which lead to rational or functional nutrition.

In a brilliant survey of what preventive medicine might accomplish, Prof. J. M. Mackintosh suggested that surgical science is still only in the clumsy experimental phase of its childhood, and that plastic surgery has only just begun to take shape. Recent advances in plastic surgery are not merely refinements in technique, but rather the progressive application of new biological knowledge; recent work on the lungs, the nerves and the blood vessels has opened up great highways for the march of science. Surgery has secured a powerful ally in biochemistry, but the mechanical expert is badly needed in the surgical repair shop, and the chemist must be called in to help in the search for non-irritant materials which can be used in surgical architecture. In preventive medicine, Prof. Mackintosh said we must recognize the environmental factors, represented by sanitary science, housing, town planning and the like, and the personal factors, with the family and social background. He stressed the importance of water supply and also atmospheric pollution: smoke prevention is one of the immediate tasks of sanitary science. On the personal side, preventive medicine stands at the door of opportunity, and the brilliant discoveries of bacteriology and biochemistry have yet to be applied. We have still to organize concerted attacks on such problems as tuberculosis, and we should also be deeply concerned with the positive aspects of prevention; there is need, for example, for a new spirit of health organization in industry, especially for the beneit of the smaller occupations and the widely distributed activities of transport and service. Finally, Prof. Mackintosh referred to the possibilities in the field of international health, and urged the importance of co-operation between the medical and other technical experts, in which each should be ready to subordinate his ideal to the common purpose.

Sir Lawrence Bragg, speaking on the place of science in industry, said that although the British have a fine record in pure science and seem to breed the right type of man for breaking new ground, initiating new branches of science and solving old problems in an unexpectedly simple way, there are three bottlenecks which are restricting the vitalizing function of science in industrial and national affairs. First, the fact that science is not yet a recognized part of a good general education, especially the higher education of those from whom the leaders of the future are likely to emerge. Secondly, he finds a very general reluctance of the most brilliant of young scientific workers to enter industry; and thirdly, the disposition of young people with a good deal of idealism to desire work directed mainly by considerations of social service. Sir Lawrence Bragg thinks that the War has indicated means of overcoming these difficulties, and finally he pointed out that when we ask what science might accomplish we should also ask what do we wish it to accomplish. The higher achievements of the human spirit are founded on man's command over Nature, and the wider and stronger science can make that foundation the higher the edifice which can be built upon it.

In summing up the Conference, Sir Harold Hartley commented that he had not found, as a teacher of chemists, the difficulty to which Sir Lawrence Bragg referred. Emphasizing a number of points which came out, such as the stimulus which science and industry mutually derive from one another, the impact of one industry on another, he referred to the general agreement on the need for greatly increased support for research, and particularly for more endowment by the State, and for making a scientific career really attractive and giving the scientific worker full encouragement and freedom to work in the way in which he can best develop his powers. There is agreement that the shortage of man-power makes it imperative to see that trained intelligence is directed into the right channels, and if the Conference contributes to a general realization of what has been done and how much still remains, it has also clearly indicated something of what is possible if we harness the brain power of the scientific worker to the improvement of the prosperity and welfare of the community.

\section{CROP PRODUCTION IN NUTRIENT SOLUTIONS}

\author{
BY SIR JOHN RUSSELL, F.R.S.
}

$S^{E}$ EVEN years ago Prof. W. F. Gericke, of the University of California, published an article in Science under the title "Hydroponies - Crop Production in Liquid Culture Media", and he followed this up in 1940 by a book, "Complete Guide to Soil-less Gardening". The idea attracted certain people very strongly, and before long it was necessary for some of the staff of the University to point out that some at least of the claims that were being put forward lacked good evidence. The method was critically but impartially investigated in Great Britain by Prof. R. H. Stoughton, of the University of Reading, Dr. G. H. Bewley, of the Cheshunt Research Station, and Messrs. W. G. Templeman and S. J. Watson, of Jealotts Hill, and it is now possible to obtain a much more complete view than could be done before.

In principle, it is the water-culture method familiar to generations of botanists: plants are grown in nutrient solutions and not in soil. But the scale is different. Instead of individual plants each in its own bottle, the plants are grown in considerable number in specially constructed troughs holding the culture solution, the seed or seedling being supported on a specially prepared bed of vegetable litter. 